\title{
Application of Constructed Wetland for Treating Runoff from the Dairy Cattle Farm Yard
}

\author{
Ludmiła Rossa', Marek Urbaniak ${ }^{1 *}$ Zuzanna Majewska' \\ 1 Institute of Technology and Life Sciences, Falenty, Al. Hrabska 3, 05-090 Raszyn, Poland \\ * Corresponding author's e-mail: m.urbaniak@itp.edu.pl
}

\begin{abstract}
Constructed wetlands (CWs) are becoming a popular solution for the treatment of rainwater discharged from hardened surfaces, because their construction and maintenance does not require large expenditures. The research on the effectiveness of treating runoff from the dairy farm yard was carried out using constructed wetland. The studied wetland was built in the form of two connected reservoirs with an area of $30 \mathrm{~m}^{2}$. In the first deep reservoir, sedimentation of suspended matter occurred, while in the second shallow reservoir, six species of aquatic plants were planted in order to assimilate nitrogen and phosphorus compounds. In the years 2014-2018, the water samples from the inflow and outflow of the constructed wetland were collected. The $\mathrm{pH}$ and electrical conductivity values, as well as nitrate nitrogen, ammonium nitrogen, phosphates phosphorus and chlorides concentrations were determined with electrochemical and photometric methods. The obtained results were statistically analyzed using the Statistica v. 7 software. In the majority of the runoff samples from the farmyard, abnormal concentration of ammonium nitrogen ( $90 \%$ of samples) and phosphate phosphorus (100\% of samples) occurred in relation to the requirements for surface waters. The values of ammonium nitrogen concentration exceeded the acceptable norms for domestic sewage discharged into waters in $31 \%$ of samples and in the case of phosphate phosphorus - in $67 \%$ of samples. The concentration of chlorides exceeded the limit values for surface water in $36 \%$ of samples. The average concentration of nitrate nitrogen did not exceed these standards. There was a high correlation between the concentration of ammonium nitrogen and the concentration of phosphate phosphorus and chlorides. The efficiency of runoff treatment from the dairy cattle farm yard was very high in the initial period of research, reaching $85.4 \%$ for ammonium nitrogen and $68.3 \%$ for phosphate phosphorus, but showed a downward trend over time for the entire period.
\end{abstract}

Keywords: runoff water, cattle farm, water quality, constructed wetland.

\section{INTRODUCTION}

Successful attempts have been made in the field of using natural and constructed wetlands to protect the environment, especially in the Nordic countries [Ulén et al., 2007]. It has been found that constructed wetlands retain nitrogen and phosphorus compounds as well as suspended material in such processes as filtration, sedimentation, assimilation of dissolved compounds by plants, nitrification and denitrification, aerobic and anaerobic degradation. The possibility of retaining phosphorus compounds adsorbed on soil particles moving during erosion is particularly important. Thus, the load of nutrients flowing into rivers and lakes is reduced, which decrease the risk of water eutrophication. The capacity of wetlands to retain biogens depends on the type of soil, rainfall intensity, types and doses of fertilizers. The effectiveness of constructed wetlands in this field was confirmed by many years of research [Bergson et al., 2015; Johannesson et al., 2015; Kynkäänniemi et al., 2013].

Currently, constructed wetlands are considered one of the most important measures to reduce the nutrient loss from rural areas to surface 
waters at a catchment scale. It is estimated that constructed wetlands can retain $20-90 \%$ nitrogen and $25-95 \%$ phosphorus. There are many technical solutions for a design of constructed wetlands, such as retention ponds, purification ponds, wide drainage ditches and many others using various species of vascular plants [Schoumans et al., 2014; Pietrzak, 2012; Feurbach, Strand, 2010].

A high concentration of various sources of organic and biogenic pollution on dairy farms may pose a risk of soil and groundwater contamination. The areas located near livestock buildings and manure storage places are especially exposed. High nutrient losses to surface water and ground water are characteristic for the built-up areas, especially hardened [Pietrzak, 2012; Rossa, Russel, 2011]. The concentration of nitrogen and phosphorus compounds in the outflow water from the built-up rural areas is much higher than from the urban areas. Hence, the solutions that reduce nutrient loss from agricultural sources should be implemented [Ulén et al., 2013]. Constructed wetlands can become a popular solution for treating rainwater in rural areas, because their construction does not require high expenditures.

In this paper, the results of the research on the effectiveness of the constructed wetland receiving rainwater runoff from a dairy farm are presented. The research was conducted at the Institute of Technology and Life Sciences in Falenty, in the years 2014-2018. The tested wetland was built as part of the SERA project "Self-evaluation and risk analysis by farmers concerning losses of nutrients and low cost remedial measure" in cooperation with SLU Uppsala in Sweden.

The aim of the presented work was to assess the possibilities of treating a rainwater runoff from the experimental dairy farm yard in the constructed wetland. In the years 2014-2018, the pH, conductivity as well as the content of ammonium nitrogen, nitrate nitrogen, phosphate phosphorus and chloride were determined in the surface runoff from the farmyard and the outflow from constructed wetland. The research allowed assessment of the degree of runoff pollution in relation to legal requirements, assessment of species composition changes and calculation of the average efficiency of treatment and its relationship with the concentration of nutrients in the inflow to the constructed wetland.

\section{MATERIALS AND METHODS}

The tested constructed wetland is located in the Masovian Voivodeship in the Pruszków district. The main purpose of this object was the treatment of the runoff water from the yard of the ITP experimental farm, which breeds dairy cattle. In the livestock buildings of the farm, two cowsheds and a covered shed, there were about 200 cattle, periodically.

On the yard with an area of $1.100 \mathrm{~m}^{2}$, there is also a cow paddock, liquid manure tank, silage silos and a tractor parking. Solid manure was transported outside the yard to manure pad, and then used to fertilize arable land and grassland. The liquid manure was discharged into a slurry tank, and after a fermentation period, it was exported to grassland and, to a lesser extent, to arable land.

The yard surface is mostly $(70 \%)$ paved. The layer of soil should be periodically removed, but most often it flows as a suspension together with the drained rainwater.

Rainwater was discharged to a $47 \mathrm{~m}$ long collecting channel, and then to two reinforced concrete wells with a diameter of $1.2 \mathrm{~m}$ each, connected in series. When the volume of runoff exceeded the usable capacity of the well, the excess water was discharged from the first well through an overflow, via a $46 \mathrm{~m}$ long pipe to the first deeper settler of the constructed wetland. The outflow from the constructed wetland was discharged into a drainage channel and then into a drainage ditch.

The two wetlands, characterized with similar area $\left(30 \mathrm{~m}^{2}\right)$, were constructed for the same purpose, namely to reduce particle, $\mathrm{N}$ and $\mathrm{P}$ load in runoff water, but their shape and design are different. The bottoms of two tanks were lined with a layer of sand $(5 \mathrm{~cm})$, anti mole netting, foil, layer of soil $(10-20 \mathrm{~cm})$ and gravel $(10-15 \mathrm{~cm})$. The height of the dike was $10 \mathrm{~cm}$ above the water level, the slopes $30-35^{\circ}$. The banks of constructed wetland as well as the inlet and outlet ducts were covered with crushed stone.

In the first, deeper settler, soil particles, insoluble organic matter and nutrients are retained. The water-soluble substances are removed, followed by a shallow area with emergent by plants: Juncus effusus, Schoenoplectus lacustris, Sparganium erectum, Iris pseudacorus, Carex riparia, Glyceria maxima.

In the years 2014-2018, the water samples from inflow and outflow of wetlands were collected in accordance with the requirements of the 


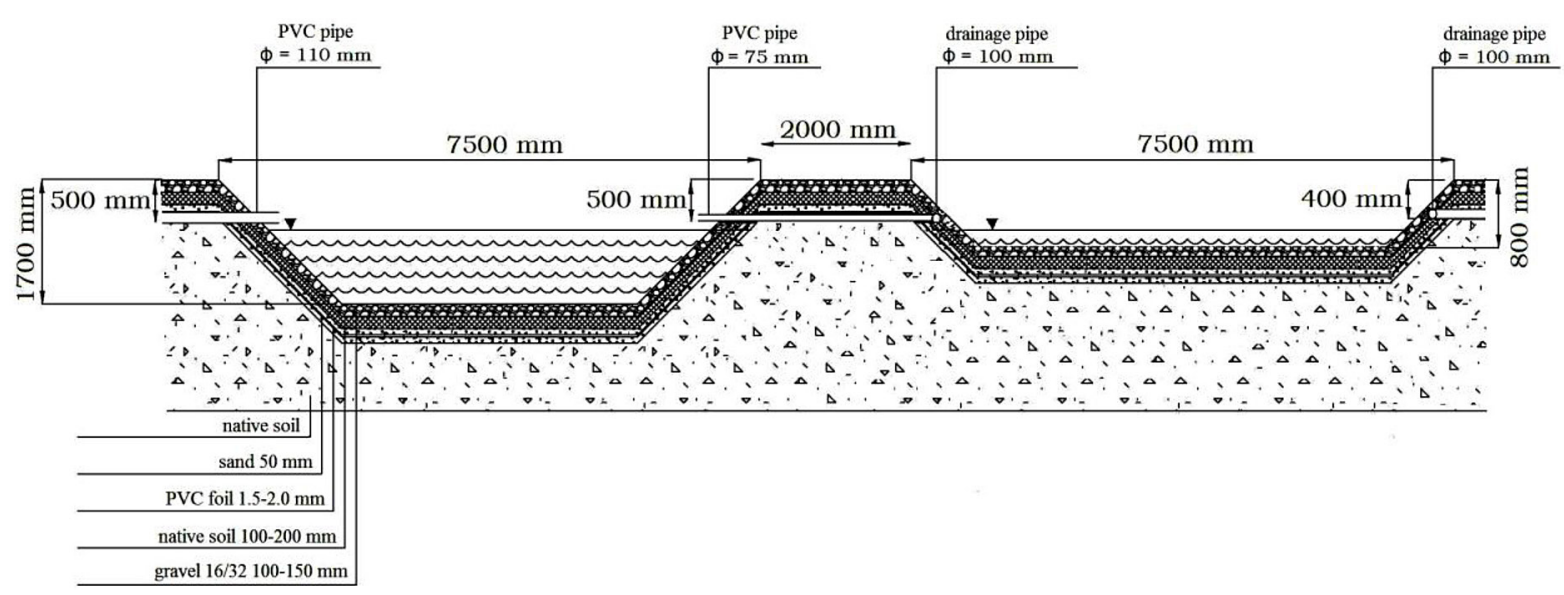

Fig. 1. Cross-section of the constructed wetland

Polish PN-EN ISO 6878:2006 standard. Thirty eight measuring series were carried out. The following samples were determined:

- $\mathrm{pH}$ - potentiometric method according to PNEN ISO 10523: 2012, using a pH meter from Mettler-Toledo,

- electrical conductivity - conductivity method according to PN-EN 27888: 1999, using a Metler-Toledo conductivity meter,

- nitrate nitrogen concentration - colorimetric method with segmented continuous flow system; addition of ammonium chloride, according to SKALAR methodology,

- ammonium nitrogen concentration - colorimetric method with segmented continuous flow system; addition of sodium salicylate, according to PN-EN ISO 15681-2 and SKALAR methodology,

- phosphate phosphorus concentration - colorimetric method with segmented continuous flow system; addition of ammonium molybdate and ascorbic acid, according to SKALAR methodology,

- chloride concentration - titration with silver nitrate, according to PN-EN-ISO 9297: 1994, using the Titrino from the Metrom company.

An assessment of the quality of raw and purified rainwater runoff was carried out based on the ordinances of the Minister of the Environment from 2014 and 2018 concerning the quality of sewage discharged into waters and classification of surface waters.

Efficiency was determined on the basis of subsequent values of the analyzed pollution indicators in inflowing $(\mathrm{Cd})$ and outflowing $(\mathrm{Co})$ rainwater from the farm yard, according to formula 1 .

$$
\mathrm{n}=(1-\mathrm{Co} / \mathrm{Cd}) \times 100, \%
$$

A statistical analysis of the correlation between tested pollution indicators and treatment efficiency was carried out with the help of the Statistica v. 7 software.

The species composition in second wetland reservoir was determined with the botanicalweight method.

\section{RESULTS AND DISCUSSION}

A high concentration of ammonium nitrogen and phosphate phosphorus in rainwater discharged from the dairy farm yard was observed. On the other hand, the nitrate nitrogen concentration was low, and the chloride concentration in the inflow to the constructed wetland was kept within an acceptable low range. The first table presents the average minimum and maximum values of the tested indicators in the years 2014-2018.

The nitrogen was observed mainly in the ammonium form, and came from the transformation of urea contained in the urine of paddock animals, as well as from the leaks occurring during the collection of liquid manure in the tank. Phosphate phosphorus was washed along with a layer of soil, straw and feed residue from the yard in the form of surface runoff. Nitrogen fertilizers were not used on the farm; therefore, high concentrations of nitrate nitrogen did not occur.

A similar ratio of $\mathrm{N}-\mathrm{NH}_{4}: \mathrm{N}-\mathrm{NO}_{3}: \mathrm{P}^{-\mathrm{PO}_{4}}$ was observed during the preceding tests of the quality of outflow from dairy yards [Rossa, 2012].

The phenomenon of transferring high amounts of phosphorus to surface runoff from hardened surfaces on farms and in small agricultural 
Table 1. The average minimum and maximum values of $\mathrm{pH}$, conductivity $(\mu \mathrm{S} / \mathrm{cm})$ and concentrations $\left(\mathrm{mg} / \mathrm{dm}^{3}\right)$ of ammonium and nitrate nitrogen, phosphate phosphorus and chlorides in rainwater inflow and outflow from constructed wetland

\begin{tabular}{|c|c|c|c|c|c|c|c|c|}
\hline Year & \multicolumn{2}{|c|}{ Type of rainwaters } & $\mathrm{pH}$ & $\mathrm{EC}[\mu \mathrm{S} / \mathrm{cm}]$ & $\begin{array}{c}\mathrm{N}-\mathrm{NH}_{4} \\
{[\mathrm{mg} / \mathrm{dm}]}\end{array}$ & $\begin{array}{c}\mathrm{P}_{-} \mathrm{PO}_{4} \\
{\left[\mathrm{mg} / \mathrm{dm}^{3}\right]}\end{array}$ & $\begin{array}{c}\mathrm{N}-\mathrm{NO}_{3} \\
{\left[\mathrm{mg} / \mathrm{dm}^{3}\right]}\end{array}$ & $\begin{array}{c}\mathrm{Cl}^{-} \\
{\left[\mathrm{mg} / \mathrm{dm}^{3}\right]}\end{array}$ \\
\hline \multirow{6}{*}{2014} & \multirow{3}{*}{ Rainwater inflow } & $\min$ & 6.60 & 0.27 & 0.19 & 0.95 & 0.01 & 8.90 \\
\hline & & $\max$ & 7.60 & 0.68 & 11.40 & 3.03 & 6.26 & 22.40 \\
\hline & & $x$ & 7.27 & 0.46 & 4.65 & 1.86 & 1.29 & 16.29 \\
\hline & \multirow{3}{*}{ Rainwater outflow } & $\min$ & 6.79 & 0.26 & 0.19 & 0.19 & 0.07 & 8.60 \\
\hline & & $\max$ & 9.33 & 0.85 & 1.97 & 2.30 & 2.15 & 27.30 \\
\hline & & $x$ & 7.65 & 0.51 & 0.68 & 0.59 & 0.38 & 16.45 \\
\hline \multirow{6}{*}{2015} & \multirow{3}{*}{ Rainwater inflow } & $\min$ & 6.84 & 0.28 & 2.45 & 2.02 & 0.02 & 15.80 \\
\hline & & $\max$ & 7.52 & 0.81 & 14.76 & 9.79 & 4.76 & 70.90 \\
\hline & & $x$ & 7.15 & 0.47 & 8.27 & 3.97 & 1.06 & 33.70 \\
\hline & \multirow{3}{*}{ Rainwater outflow } & $\min$ & 6.77 & 0.26 & 0.15 & 0.89 & 0.03 & 11.70 \\
\hline & & $\max$ & 7.35 & 1.07 & 11.40 & 7.73 & 6.29 & 60.20 \\
\hline & & $x$ & 7.09 & 0.57 & 5.00 & 2.49 & 1.24 & 32.25 \\
\hline \multirow{6}{*}{2016} & \multirow{3}{*}{ Rainwater inflow } & $\min$ & 7.04 & 0.44 & 0.08 & 4.32 & 0.01 & 38.00 \\
\hline & & $\max$ & 7.41 & 1.13 & 29.66 & 9.51 & 9.10 & 62.50 \\
\hline & & $x$ & 7.25 & 0.65 & 15.32 & 6.02 & 1.52 & 47.01 \\
\hline & \multirow{3}{*}{ Rainwater outflow } & $\min$ & 6.88 & 0.30 & 0.01 & 0.75 & 0.03 & 0.30 \\
\hline & & $\max$ & 7.62 & 0.72 & 9.01 & 6.03 & 3.31 & 41.20 \\
\hline & & $x$ & 7.26 & 0.46 & 2.72 & 2.35 & 0.92 & 24.28 \\
\hline \multirow{6}{*}{2017} & \multirow{3}{*}{ Rainwater inflow } & $\min$ & 6.95 & 0.50 & 6.55 & 4.39 & 0.01 & 1.90 \\
\hline & & $\max$ & 8.07 & 1.36 & 34.81 & 10.93 & 0.55 & 15.70 \\
\hline & & $x$ & 7.44 & 0.77 & 16.22 & 6.75 & 0.16 & 10.53 \\
\hline & \multirow{3}{*}{ Rainwater outflow } & $\min$ & 6.99 & 0.49 & 1.06 & 2.36 & 0.02 & 1.80 \\
\hline & & $\max$ & 7.87 & 1.33 & 21.81 & 7.91 & 0.22 & 14.50 \\
\hline & & $x$ & 7.21 & 0.71 & 8.99 & 4.58 & 0.14 & 6.27 \\
\hline \multirow{6}{*}{2018} & \multirow{3}{*}{ Rainwater inflow } & $\min$ & 7.22 & 0.57 & 0.06 & 2.98 & 0.00 & 18.40 \\
\hline & & $\max$ & 7.76 & 0.67 & 3.30 & 5.10 & 0.12 & 28.10 \\
\hline & & $x$ & 7.45 & 0.63 & 1.37 & 3.93 & 0.06 & 23.93 \\
\hline & \multirow{3}{*}{ Rainwater outflow } & $\min$ & 7.12 & 0.56 & 0.66 & 2.52 & 0.02 & 3.70 \\
\hline & & $\max$ & 7.53 & 0.73 & 3.99 & 4.73 & 0.20 & 24.60 \\
\hline & & $x$ & 7.35 & 0.63 & 1.93 & 3.58 & 0.09 & 17.08 \\
\hline
\end{tabular}

catchments is described in the literature on the use of built wetlands to reduce the nutrient loss in rural areas [Ulén et al., 2013; Kynkäänniemi et al., 2013]. The management of surface runoff from hardened surfaces in rural areas, despite its significant biogenic compound contamination, is not regulated by the Polish law. According to the amended Water Law (Journal of Laws of 2017, item 1566) drainage of rainwater and snowmelt is required by the sewage system within the administrative boundaries of cities. The requirements relate to the purification of rainwater runoff from industrial areas, storage areas, transport bases, ports, airports, cities, roads classified as national, voivodship or poviat roads, as well as car parks with an area over 0.1 ha and fuel distribution facilities, up to level $100 \mathrm{mg} / \mathrm{dm}^{3}$ of total suspended solids and $15 \mathrm{mg} / \mathrm{dm}^{3}$ of petroleum hydrocarbons [Reg., 2014].The limit values required in domestic sewage discharged into waters and into the ground were applied for assessing the degree of pollution of rainwater from the farmyard [Reg., 2014].

In relation to the requirements for domestic sewage, excessive concentrations of ammonium nitrogen were found in the inflow of rainwater, and sporadically in the outflow of rainwater discharged from the constructed wetland. Exceeded values of permissible phosphate phosphorus concentration in the incoming rainwater and - less frequently - in the outflow from the wetland, were observed. On the other hand, no exceedances of permissible nitrate nitrogen and chloride concentrations were observed. In most of the surface runoff samples, there was an excessive concentration of ammonium nitrogen and phosphorus phosphorus in relation to the surface water requirements. The concentrations of nitrate 
nitrogen and chloride significantly less often exceeded the permissible values for surface waters. Table 2 presents the number of samples in which the values of tested indicators were exceeded for domestic sewage discharged into waters. (Reg., 2014).

In both cases, in the inflow of contaminated rainwater from the farmyard and the outflow from the constructed wetland, statistically significant correlations between the concentrations of ammonium nitrogen, phosphate phosphorus, chlorides and conductivity were observed. The correlation coefficients are presented in Table 3.

The ammonium nitrogen and phosphate phosphorus concentrations were also correlated with conductivity, as shown in surface charts using nonlinear modeling in Figures 2 and 3.

In many constructed wetlands, the concentration of total nitrogen and phosphorus in the outflow is positively correlated with the concentration in the wastewater flowing into the treatment plant and negatively with their load. [Pavlineri, Skoulikidis, Tsihrintzis, 2017]. There was also a correlation between the concentration of nitrogen and phosphorus in the wastewater treatment plant [Jakubaszek, Wojciech, 2014].

In the tested constructed wetland, the treated runoff was from the yard of a large farm, where a herd of dairy cattle was kept. Typical agricultural pollution was observed - ammonium nitrogen and phosphate phosphorus, originating from animal excrements, natural fertilizers and waste from feed production in characteristic proportions [Lisowska-Mieszkowska, 2014; Pietrzak 2009].

In the years 2014-2018, the average treatment efficiency in the constructed wetland was $58.7 \%$ ammonium nitrogen, $50 \%$ phosphate phosphorus, $54.8 \%$ nitrate nitrogen and $32.3 \%$ chlorides. The changes in the average annual efficiency in subsequent years of the study are shown in Figure 4. In the initial study period, the efficiency of removing excess ammonium nitrogen and phosphate phosphorus compounds was high, ranging from

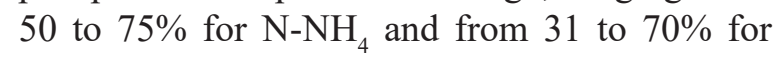
$\mathrm{P}-\mathrm{PO}_{4}$. The reduction of treatment efficiency in 2018 was probably due to the periodic leakage of the sewage system. The nitrate nitrogen concentrations were so low $\left(0.75 \mathrm{mg} / \mathrm{dm}^{3}\right.$ on average $)$

Table 2. Number of rainwater samples (\%) in which the limit values or waste water and surface waters were exceeded

\begin{tabular}{|c|c|c|c|c|}
\hline \multirow{2}{*}{ Classification type } & \multicolumn{3}{|c|}{ Rainwaters } \\
\cline { 2 - 5 } & \multicolumn{2}{|c|}{ inflow } & \multicolumn{2}{c|}{ outflow } \\
\cline { 2 - 5 } & surface waters & sewage & surface waters & sewage \\
\hline${\mathrm{P}-\mathrm{PO}_{4}}^{\mathrm{N}-\mathrm{NH}_{4}}$ & 100 & 67.7 & 100 & 27.5 \\
\hline $\mathrm{N}-\mathrm{NO}_{3}$ & 89.7 & 30.8 & 77.5 & 0 \\
\hline $\mathrm{Cl}$ & 35.9 & 0 & 7.7 & 0 \\
\hline
\end{tabular}

Table 3. Spearman's correlation coefficients between tested indicators of pollution in inflow and outflow from constructed wetland

\begin{tabular}{|c|c|c|c|c|c|c|}
\hline & $\mathrm{N}-\mathrm{NH}_{4}$ & $\mathrm{P}_{-} \mathrm{PO}_{4}$ & $\mathrm{~N}-\mathrm{NO}_{3}$ & $\mathrm{pH}$ & EC & $\mathrm{Cl}$ \\
\hline \multicolumn{7}{|c|}{ inflow to the CW } \\
\hline $\mathrm{N}-\mathrm{NH}_{4}$ & 1.00 & $0.60^{* *}$ & -0.17 & -0.12 & $0.39^{*}$ & $0.52^{* *}$ \\
\hline $\mathrm{P}-\mathrm{PO}_{4}$ & & 1.00 & -0.19 & 0.07 & $0.76^{* *}$ & $0.67^{* *}$ \\
\hline $\mathrm{N}-\mathrm{NO}_{3}$ & & & 1.00 & 0.00 & -0.32 & -0.08 \\
\hline $\mathrm{pH}$ & & & & 1.00 & 0.07 & -0.19 \\
\hline $\mathrm{EC}$ & & & & & 1.00 & $0.50^{* *}$ \\
\hline $\mathrm{Cl}$ & & & & & & 1.00 \\
\hline \multicolumn{7}{|c|}{ outflow from the CW } \\
\hline $\mathrm{N}-\mathrm{NH}_{4}$ & 1.00 & $0.67^{* *}$ & -0.22 & -0.24 & $0.32^{*}$ & $0.42^{*}$ \\
\hline $\mathrm{P}-\mathrm{PO}_{4}$ & & 1.00 & -0.29 & -0.03 & $0.37^{*}$ & 0.26 \\
\hline $\mathrm{N}-\mathrm{NO}_{3}$ & & & 1.00 & 0.17 & -0.22 & -0.16 \\
\hline $\mathrm{pH}$ & & & & 1.00 & -0.18 & -0.20 \\
\hline $\mathrm{EC}$ & & & & & 1.00 & $0.37^{*}$ \\
\hline $\mathrm{Cl}$ & & & & & & 1.00 \\
\hline
\end{tabular}

* correlation significant for $\mathrm{p}<0.05, * *$ correlation significant for $\mathrm{p}<0.01$. 


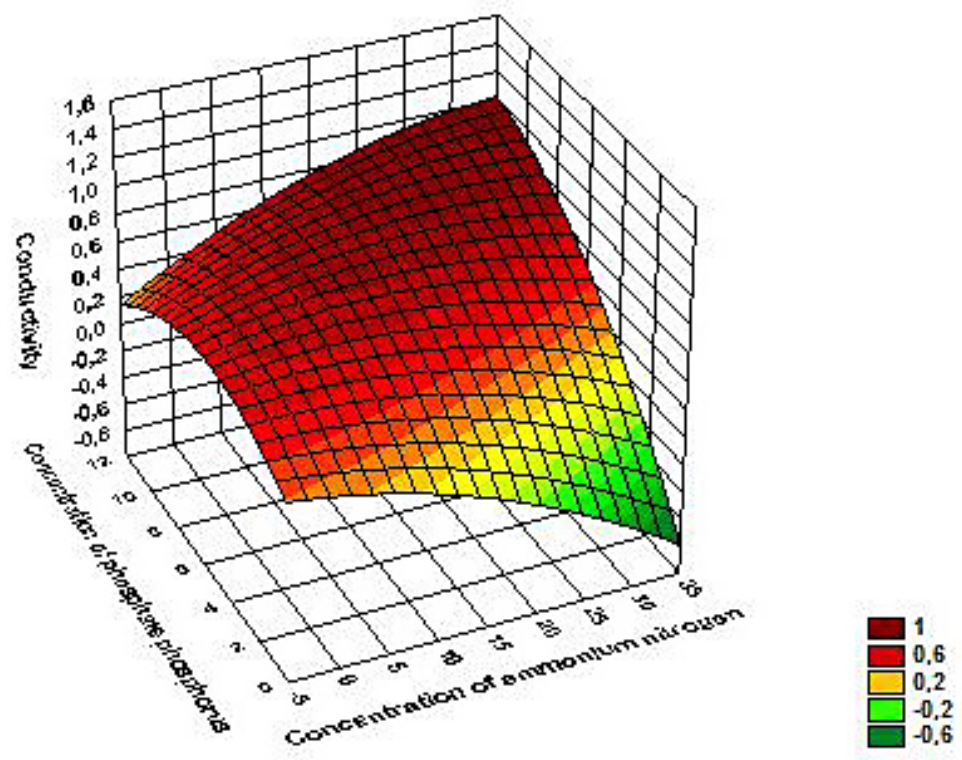

Fig. 2 Ammonium nitrogen concentration $\left[\mathrm{mgN}^{-N_{4}} / \mathrm{dm}^{3}\right]$ in relation to phosphate phosphorus

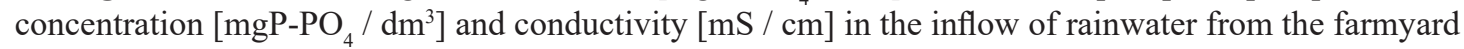
to the constructed wetland

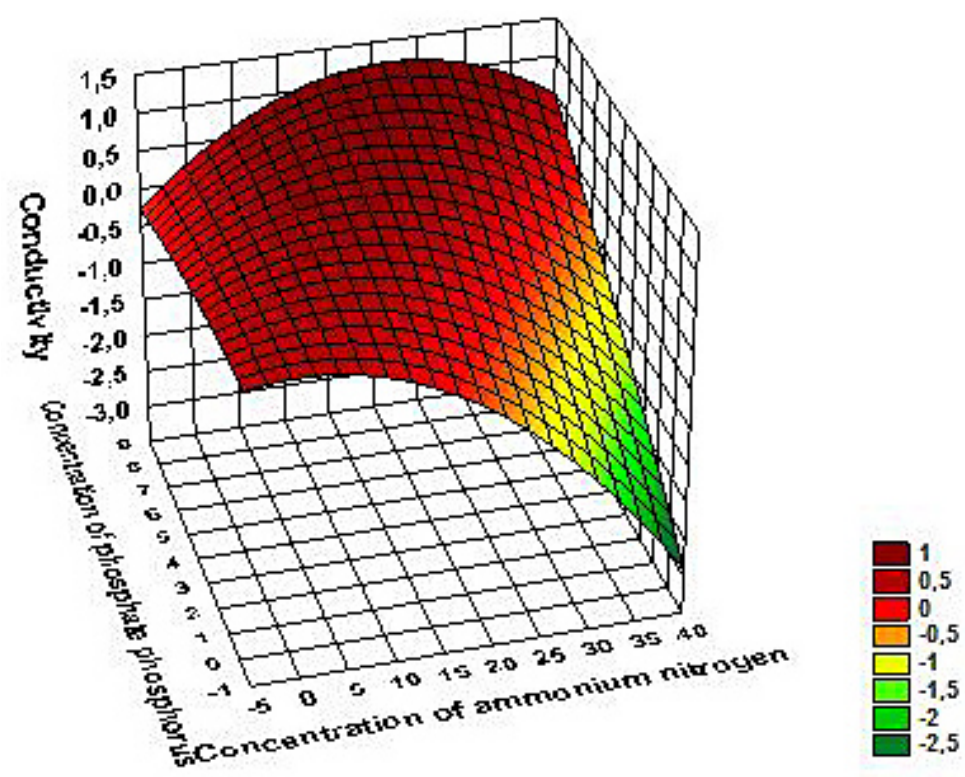

Fig. 3 Ammonium nitrogen concentration $\left[\mathrm{mgN}-\mathrm{NH}_{4} / \mathrm{dm}^{3}\right]$ in relation to phosphate phosphorus concentration $\left[\mathrm{mgP}-\mathrm{PO}_{4} / \mathrm{dm}^{3}\right]$ and conductivity $[\mathrm{mS} / \mathrm{cm}]$ in the outflow of rainwater from constructed wetland

that it is difficult to assess the degree of their removal, while the efficiency of chloride removal stabilized at 42 to $47 \%$.

There was a significant correlation $(\mathrm{p}<0.01)$ between the efficiency of ammonium nitrogen and phosphate phosphorus removal $(\mathrm{r}=0.67)$, while there were no statistically significant correlations between the initial concentration of the compound and the effectiveness of its purification.
The efficiency of removing contaminants in the tested constructed wetland with horizontal flow was similar to that described in the literature. The nutrient retention efficiency amounts was described as from 40 to $55 \%$ of total nitrogen and $40-60 \%$ of total phosphorus for wastewater [Vymazal, 2007], 20-19\% N and $25-100 \%$ P for the outflows from fields [Pietrzak, 2012] and 36\% phosphorus from watercourses 


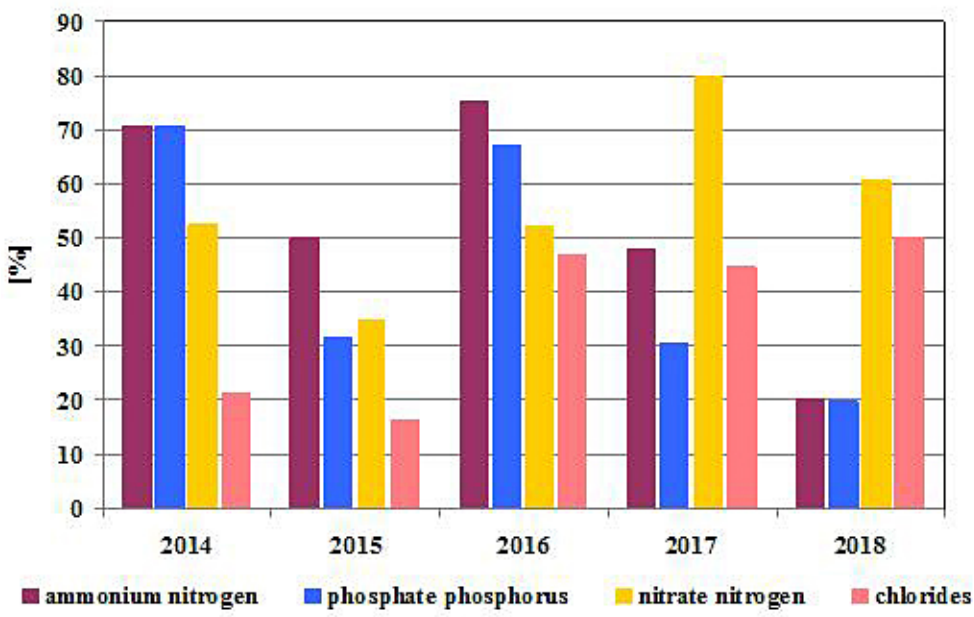

Fig. 4 Average annual efficiency [\%] of the removal of ammonium nitrogen, phosphate phosphorus, nitrate nitrogen and chloride in the years 2014-2018

and ditches [Kynkäänniemi, Ulén, Torstensson, Tonderski, 2013].

Relatively large phosphorus retention is associated with the presence of the first deeper reservoir, which acts as a "phosphorus trap", retained by sedimentation of suspended solids, according to the mechanism described in the literature [Wu, Zhang, Li, Fan, Zou, 2013; Ulen. Pietrzak, Tonderski, 2013].

In the years 2014-2018, the species composition of the plants changed significantly. At the beginning of the study, a reduction in the presence of the Sparganium erectum and the Iris pseudacorus was observed, then the Juncus effusus disappeared, while Schoenoplectus lacustris and the margin sedge Carex riparia occurred. There was a clear expansion of the hydrophyte Gliceria maxima.

Figure 5 presents the changes in the species composition of plants in the constructed wetland during the research work.

The expansion was caused by better properties of the Gliceria maxim compared to other hydrophytes - high botanical resistance, good evapotranspiration and the best ability to accumulate the nitrogen and phosphorus compounds [Jucherski, Walczowski, 2012: Obarska-Pempkowiak, 2002].

\section{CONCLUSIONS}

1. The main pollutants in the outflow of rainwater from the dairy farm yard were the compounds of ammonium nitrogen and phosphate phosphorus.

2. The concentrations of ammonium nitrogen compounds exceeded the permissible values for the treated domestic sewage in 30.8\% of samples, and concentrations of phosphate phosphorus compounds in $67.7 \%$ of the collected rainwater outflow samples.

3 . There was a strong positive correlation between the concentration of ammonium nitrogen and phosphate phosphorus, both in the inflow $(r=0.6, p<0.01)$ and in the outflow $(r=0.67$,
2016

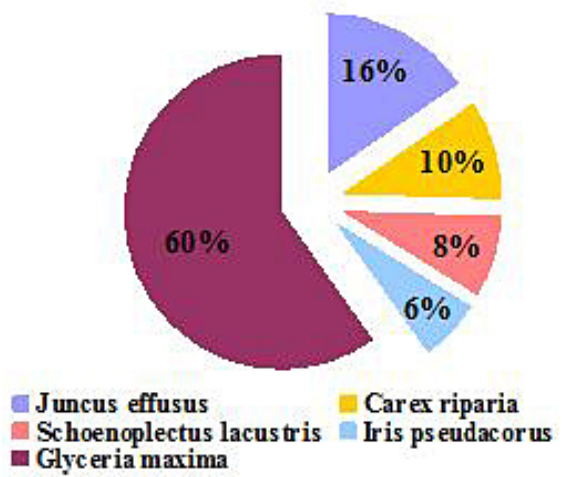

2018

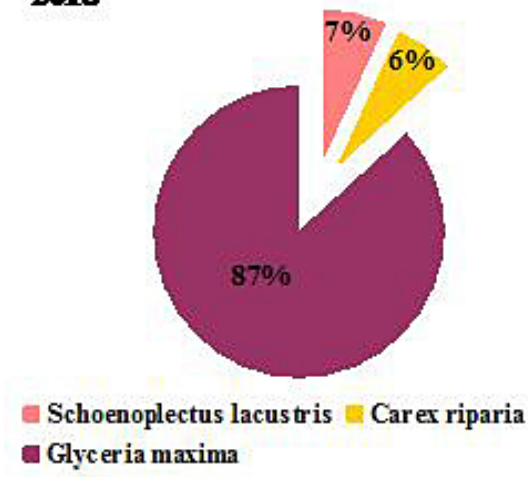

Fig. 5. Percentage species composition of plants in the constructed wetland 
$\mathrm{p}<0.01$ ) of waters from constructed wetland.

4. In the years 2014-2018, the average treatment efficiency in the constructed wetland was $58.7 \%$ for ammonium nitrogen and $50 \%$ for phosphate phosphorus.

5. In the second constructed wetland reservoir, there was a permanent expansion of Gliceria Maxima.

\section{REFERENCES}

1. Act of 10 July New Water Law (Journal of Laws 2017, item 1566).

2. Bergström L., Kirchmann H., Djodjic F., Kyllmar K., Ulén B., Liu J., Andersson H., Aronsson H., Börjesson G., Kynkäänniemi P., Svanbäck A., Villa A. 2015. Turnover and Losses of Phosphorus in Swedish Agricultural Soils: Long-Term Changes, Leaching Trends, and Mitigation Measures. Journal of Environmental Quality (special edition) Vol. 44 512-523.

3. Feuerbach P., Strand J. 2010. Water and Biodiversity in the agricultural landscape EPA Sweden p. 50

4. Jakubaszek A., Wojciech M. 2014. Statistical analysis of nitrogen in the soil of constructed wetland with horizontal sub-surface flow CEER 2014. University of Zielona Góra, Vol. 12(1), 33-43.

5. Johannesson K.M., Kynkäänniemi P., Ulén B., Weisner S.E.B., Tonderski K.S. 2015. Phosphorus and particle retention in constructed wetlands-A catchment comparison. Ecological Engineering. Viol. 80, 20-31.

6. Jucherski A., Walczowski A. 2012. Influence of selected macrophytes on sewage treatment effectiveness in the slope soil-vegetation filtration beds. Problems of Agricultural Engineering, 1(75), 115-124.

7. Kynkäänniemi P. 2014. Small wetlands designers for phosphorus retention in Swedish agricultural areas. SLU Acta Universitatis Agriculturale Sueciae No 2014:70 Upsala, pp. 62.

8. Kynkäänniemi P., Ulén B., Gunnar Torstensson G., Tonderski K. S. 2013. Phosphorus Retention in a Newly Constructed Wetland Receiving Agricultural Tile Drainage Water. J. Environ. Qual., 42, 596-605.

9. Lisowska-Mieszkowska E. 2014. Controlling and limiting the emission of ammonia from the agricultural sources. Actions undertaken internationally. Economy and Environment, 3(50), 130-142.

10. Obarska-Pempkowiak H. 2002. Treatment wetlands. Gdansk University of Technology, Gdansk, pp. 214.

11. Pavlineri N., Skoulikidis N., Tsihrintzis V. A. 2017. Constructed Floating Wetlands: A review of research, design, operation and management aspects, and data meta-analysis. Chem. Eng. J., 308 $1120-1132$.

12. Pietrzak S. 2009. Good practices in reducing ammonia nitrogen emissions from fertilizers. Instructional Materials, IMUZ, pp. 13.

13. Pietrzak S. 2012. Priority measures to reduce nitrogen and phosphorus losses from agriculture to protect water quality. ITP Falenty, Baltic Compass p.34.

14. PN-EN 25667-2 Guidance on sampling techniques PKN 1999.

15. PN-EN ISO 10523 Determination of PH PKN 2012.

16. PN-EN 27888 Detrmination of the specific electrical conductivity PKN 1999.

17. PN-EN ISO 7150-1 Determination of ammonium PKN 2002.

18. PN-EN-ISO 9297 Determination of chloride PKN 1994.

19. Rossa L. 2012. Nutrient pollutants in soil and ground water in the vicinity of the dairy cattle farms. WaterEnvironment - Rural areas, 1(37), 119-137.

20. Rossa L., Russel S. 2011. Chemical and microbiological pollution of runoff water from cattle farm. Advances of Agricultural Sciences Problem, no. $565,225-235$.

21. Regulation of the Minister of Environment of 18 November 2014 on the conditions to be met when introducing sewage into water or soil and on substances particularly harmful to the aquatic environment (Journal of Laws 2014, item 1800).

22. Regulation of the Minister of Environment of 21 July 2016 on status classification of surface water bodies and environmental quality standards for priority substances (Journal of Laws 2016, item 1187).

23. Schoumans O.F., Chardon W.J., Bechmann M.E., Gascuel-Odoux C., Hofman G. Kronvang B., Rubæk G.H., Ulén B., Dorioz J.M. 2014 Mitigation options to reduce phosphorus losses from the agricultural sector and improve surface water quality: A review. Science of the Total Environment, 468, 1255-1266.

24. Ulén B., Bechmann M., Fölster J., Jarvie HP., Tunney H. 2007. Agriculture as a phosphorus source for eutrophication in the north-west European countries, Norway, Sweden, United Kingdom and Ireland. Soil Use and Management,. 23, 5-15.

25. Ulén B., Pietrzak S., Tonderski K.: 2013. Self- evaluation of farms for improved nutrient management and minimised environmental impact. ITP Falenty, pp. 99.

26. Wu, H.; Zhang, J.; Li, C.; Fan, J.; Zou, Y. 2013. Mass balance study on phosphorus removal in constructed wetland microcosms treating polluted river water. CLEAN Soil Air Water, 41, 844-850.

27. Vymazal J. 2007. Removal of nutrients in various types of constructed wetlands. Sci. Total. Environ. 380, 48-65. 